\title{
COMMENTARY
}

\section{Give or take? Intravenous immunoglobulin or plasma exchange for Guillain-Barré syndrome}

\author{
Richard AC Hughes* \\ See related research by El-Bayoumi et al., http://ccforum.com/content/15/4/R164
}

\begin{abstract}
A new randomised controlled trial suggested that plasma exchange hastened removal from the ventilator in mechanically ventilated children with Guillain-Barré syndrome compared with intravenous immunoglobulin. Two larger trials in adults showed the opposite result.
\end{abstract}

In this issue El-Bayoumi and colleagues [1] publish the results of a randomised controlled trial comparing intravenous immunoglobulin (IVIg) with plasma exchange in mechanically ventilated children with Guillain-Barré syndrome (GBS). Any randomised study in an uncommon condition such as GBS deserves serious attention and a study like this in children is especially valuable since almost all previous studies were done entirely in adults $[2,3]$. GBS is less common in children and has been said to pursue a milder course, but this is uncertain and there are no known differences in its electrophysiology or pathology from GBS in adults so that differences in treatment response are not expected. The conclusion from previous trials summarised in a Cochrane review was that plasma exchange and IVIg have equivalent efficacy in terms of improvement in disability after 4 weeks, the primary outcome in the review, duration of ventilation and long-term disability [4]. Furthermore, in the largest trial, adding IVIg after plasma exchange did not make a significant difference to any outcome [5]. Despite the efficacy of IVIg and plasma exchange, corticosteroids are ineffective, although their use for other coincident medical conditions is not harmful.

*Correspondence: rhughes11@btinternet.com

Cochrane Neuromuscular Disease Group, MRC Centre for Neuromuscular Disease, PO Box 114, National Hospital for Neurology and Neurosurgery, 8-11 Queen Square, London WC1N 3BG, UK
El-Bayoumi and colleagues randomised severely affected children with GBS to a standard course of one plasma volume plasma exchange on five consecutive days or a standard IVIg course of $0.4 \mathrm{~g} / \mathrm{kg}$ infusions also on five consecutive days. They report that the outcome was similarly favourable in both groups but that the duration of mechanical ventilation was significantly shorter in the plasma exchange group (median 11 days, interquartile range 11.0 to 13.0 ) than in the IVIg group (median 13 days, interquartile range 11.3 to 14.5 ), a two day difference, which is large enough to be perceived as worthwhile if it were a genuine difference. However, this result may have been biased by the fact that the assessors were not masked from knowing which regimen the participant had received. Furthermore, in both previous large trials the duration of ventilation was shorter with IVIg than plasma exchange. In the first trial, the median duration of ventilation was 27 days (95\% confidence interval (CI) 13 to 97 ) in 29 patients treated with IVIg and 34 days (95\% CI 12 to 97 ) in 34 patients with plasma exchange [6]. In the second trial, the median duration of ventilation was 26 days (95\% CI 18.4 to 38.2$)$ in 44 patients treated with IVIg and 29 days (95\% CI 19.1 to 45.9 ) in 40 patients treated with plasma exchange [5]. There is no easy method for performing a meta-analysis of medians but inspection of these results suggests that there is no significant difference in efficacy of IVIg and plasma exchange for duration of requirement for artificial ventilation. In the El-Bayoumi and colleagues trial, no serious adverse events were encountered. However, in five trials for which information was available for the Cochrane review, there were more adverse events in the plasma exchange than the IVIg group [4]. While IVIg is the preferred treatment in many centres because of its convenience, simplicity and greater comfort for the patient, the ElBayoumi and colleagues trial results support the conclusion of the Cochrane review that intravenous immunoglobulin and plasma exchange are equally efficacious. Plasma exchange is therefore an acceptable treatment for GBS instead of IVIg, especially in resource-poor settings and in an ICU where good facilities for the procedure are readily available. 


\section{Abbreviations}

Cl, confidence interval; IVlg, intravenous immunoglobulin; GBS, Guillain-Barré syndrome.

\section{Competing interests}

$\mathrm{RACH}$ has or has had consultancies with companies that manufacture immunoglobulin, Baxter, LFB, Octapharma and Talecris.

\section{Author's information}

RACH is Emeritus Professor of Neurology at King's College London. He has had a career-long interest in GBS and its management. He was the founding chief editor of the Cochrane Neuromuscular Disease Review Group and has led randomised controlled trials and written Cochrane reviews on GBS. He is now President of the European Federation of Neurological Societies.

Published: 28 July 2011

\section{References}

1. El-Bayoumi MA, El-Rafaey AM, Abdulkader AM, El-Assmy MMA, Alwakeel AA, El-Tahan HM: Comparison of intravenous immunoglobulin and plasma exchange in treatment of mechanically ventilated children with Guillain-Barré syndrome: a randomized study. Crit Care 2011, 15:R164.
2. Hughes RA, Swan AV, Raphaël JC, Annane D, van Koningsveld R, van Doorn PA: Immunotherapy for Guillain-Barré syndrome: a systematic review. Brain 2007, 130:2245-2257

3. Raphaël JC, Chevret S, Hughes RAC, Annane D: Plasma exchange for Guillain-Barré syndrome (Cochrane review update). Cochrane Database Syst Rev 2007:CD001798.

4. Hughes RA, Swan AV, van Doorn PA: Intravenous immunoglobulin for Guillain-Barré syndrome. Cochrane Database Syst Rev 2010:CD002063.

5. Plasma Exchange/Sandoglobulin Guillain-Barré Syndrome Trial Group: Randomised trial of plasma exchange, intravenous immunoglobulin, and combined treatments in Guillain-Barré syndrome. Lancet 1997, 349:225-230.

6. van der Meché FGA, Schmitz PIM, Dutch Guillain-Barré Study Group: A randomized trial comparing intravenous immune globulin and plasma exchange in Guillain-Barré syndrome. New Engl J Med 1992, 326:1123-1129.

doi:10.1186/cc10312

Cite this article as: Hughes RAC: Give or take? Intravenous immunoglobulin or plasma exchange for Guillain-Barré syndrome. Critical Care 2011, 15:174. 